\title{
An Analysis on the Relation Structure of the Causes of Impoverished College Students' Self-Confidence
}

\author{
Xiaoyi Peng, Jing Li* \\ Quality Development Institute \\ Kunming University of Science and Technology \\ Kunming, China \\ q1397612334@qq.com, 254201056@qq.com*
}

\begin{abstract}
As a common problem among impoverished college students, lack of self-confidence seriously affects their daily life and study. Therefore, improving the self-confidence of impoverished college students has become a key problem to be solved in higher education. Based on the theory of system engineering, the interpretative structural modeling of the reasons for the lack of self-confidence of impoverished college students is established for revealing the relationship of the reasons for the lack of self-confidence among impoverished college students. From the study, the fundamental reasons, the surface reasons and the root reasons of affecting the lack of self-confidence are found, and some corresponding countermeasures are put forward. The findings provide some references for training and improving the self-confidence of impoverished college students.
\end{abstract}

Keywords-Impoverished university students; Self-confidence; Interpretative structural modeling method; The reason

\section{INTRODUCTION}

According to the incomplete statistics, at present, in China's colleges and universities, the average proportion of students with financial difficulties is $20 \%$, of which the proportion of special hardship students is $8 \%$. The average proportions in agriculture, forestry, and teacher training schools are even more than $30 \%$, with the special hardship students accounting for over $15 \%$. Among the college students with psychological problems, $37.96 \%$ lacked self-confidence and $23.27 \%$ felt "inferiority".[1] After the 1990s, with the expansion policy of higher education enrollment and the implementation of the parallel charge system, impoverished college students, as a special group in colleges and universities, have received considerable attention from universities, education systems, and all walks of life.[2] Due to the special circumstances of impoverished college students, economic, academic and other pressure has brought a series of negative problems to them, such as gaucheness and autism. Among them, the lack of selfconfidence has become a common problem among impoverished college students, and it affects their daily life and learning of different degrees. Therefore, raising the selfconfidence of impoverished college students is urgent and necessary, and immediate solutions are required in college education.[3]

Self-confidence is the individual's trust in his knowledge, abilities, behavior, judgments and other aspects, and it is a relatively stable personality trait, which plays an important role in the development of the individual's personality structure and mental activity. The period of college education is not only a crucial stage for the growth of individual talents, but also an important period for forming their values and cultivating healthy personality. The establishment of self-confidence in this period directly affects the employment, life attitude and even the entire life of college students. Thus, it plays a decisive role in the future development of individuals. However, impoverished college students' self-confidence deficiency is serious.[4] Therefore, in order to effectively improve the selfconfidence of impoverished college students, it is necessary to analyze the root factors that affect self-confidence deficiency of impoverished college students. In view of a large number of reasons for self-confidence deficiency and the complex interactions of them, in this article, the system engineering theory and the interpretive structural model method will be adopted to analyze the relationship structures of these factors. Furthermore, in this article, the root factors of self-confidence deficiency will be found out, and some corresponding countermeasures and suggestions will also be proposed.

\section{THE CONSTRUCTION OF INTERPRETATIVE STRUCTURAL MODELS FOR IMPOVERISHED COLLEGE STUDENTS' LOSS OF SELF-CONFIDENCE}

\section{A. Interpretative Structural Modeling Introduction}

Interpretive Structural Modeling proposed by J. Warfield in the United States in 1973 is regarded as a method of analyzing complex social-economic system problems. Its characteristic is to decompose the complicated system into several subsystems, make use of people's practical experience, knowledge and the help of the electronic computers, and finally make the system form a multistage hierarchical structural model[5]. As a conceptual model, ISM can transform ambiguous ideas and opinions into intuitive models with good structural relationships. Therefore, it is widely used, ranging from international issues to regional economic development, business problems, and even individual-scope issues, when ISM can be employed to establish the structural model, and analyze the complex and unclear system [6].

\section{B. The Process of the Primary ISM Method}

In this section, the major process of the primary ISM method is introduced:

Step 1, determine the system element $s_{i}(i=1,2, n)$; the set of these elements is denoted by $N=\left\{s_{i} / i=1,2, n\right\}$. 
Step 2, determine the adjacency matrix A: according to the relationship between every pair of elements, the adjacent matrix $A$ can be drawn as follows(1):

$$
A=\left(a_{i j}\right)_{v * v}
$$

where

$$
a_{i j}=\left\{\begin{array}{l}
1 \text { there is the relationship between } s_{i} \text { and } s_{j} \\
0 \text { there is no relationship between } s_{i} \text { and } s_{j}
\end{array}\right.
$$

Step 3, determine the reach-ability matrix $M$ : to any adjacency matrix A, a corresponding unique reach-ability matrix $M$ exists, when the two being related in the (2)

$$
(A+I)^{n-1} \neq(A+I)^{n}=(A+I)^{n+1}=M
$$

where $I$ is the identity matrix; the exponent $n$ is a positive integer that is less than the number of elements in the set $N$, and the operations are Boolean. The matrix $M$ is the reachability matrix of $A$.

Step 4, decompose the system elements into different levels: the reach-ability matrix $M$ induces a partition on its index set into $k$ blocks called levels, and the set of these levels is denoted by $L(n)$, i.e., $L(n)$ can be drawn as follows(3):

$$
L(n)=L_{1} ; L_{2} ; \cdots ; L_{k}
$$

For purposes of stating an algorithm for finding the levels, let $L_{0}=\Phi$, the null set. Then the levels may be found iteratively, beginning with $L_{1}$, from the (4)

$$
\begin{array}{r}
L_{p}=\left\{s_{i} \in N-L_{0}-L_{1}-\cdots-L_{p-1} / R_{p-1}\left(s_{i}\right)\right. \\
\left.=R_{p-1}\left(s_{i}\right) \cap A_{p-1}\left(s_{i}\right)\right\}
\end{array}
$$

where $p=1,2, \cdots, k \cdot R_{p-1}\left(s_{i}\right)$ and $A_{p-1}\left(s_{i}\right)$ are the subsets of $N-L_{O}-L_{1}-\cdots-L_{P-1}$ that is reachable from $s_{i}$, respectively, antecedent to $s_{i}$, i.e., $R_{p-1}\left(s_{i}\right)$ and $A_{p-1}\left(s_{i}\right)$ can be drawn as follows(5):

$$
\begin{aligned}
& R_{P-1}\left(s_{i}\right)=\left\{s_{i} \in N-L_{0}-L_{1}-\cdots-L_{P-1} / m_{i j}=1\right\} \\
& A_{P-1}\left(s_{i}\right)=\left\{s_{i} \in N-L_{0}-L_{1}-\cdots-L_{P-1} / m_{j i}=1\right\}
\end{aligned}
$$

These subsets may be found by inspection from rows, respectively, and columns of $\mathrm{M}$.

Step 5, establish ISM: the order of rows and columns of the reach-ability matrix is newly arranged according to the levels of elements, and then ISM is established.

\section{The Determining Factors of Impoverished College Students' Self-Confidence Absence}

In the research on the causes of College Students' selfconfidence deficiency, Jia Wenhua and Liang Feiqin[7-8] believe that the reason for the formation of students' inferiority consciousness is the misapprehension between institutional culture of the school and students' understanding of themselves, the campus material culture and students' interpretation, the teachers' spiritual culture environment and students' behavior. Jiang Zhihong[9] considers that the reasons for the lack of selfconfidence of college students are the family life, the defect of the family education mode, the trauma of the college entrance examination, the conflict of self-esteem and self-contempt, and the negative evaluation of others. In this case, he proposes three basic methods of building students' self-confidence. In addition to that, Liu Jia[10] thinks there are four forms of expression about college students' inferiority: vulnerable to excitement, odd personality, radical thoughts, and sensitive paranoia, as well as four causes: impoverished learning, family reasons and communication barriers. What Wang Lili and Pan Zongqiu [1,11] believe is that the current psychological situation of impoverished students in colleges and universities is extremely complex and is generally manifested as a contradictory personality, which results from the conflict between the impoverished culture and the mainstream culture accepted by the impoverished students. At the same time, the marginalization of the campus environment and interpersonal interaction has aggravated the lack of self-confidence of the impoverished students. Zhu Lin[12] believes that the impoverished students face more pressure and frustration due to their special living environment and family conditions. In this case, they cannot adapt well to the school environment and have psychological problems, which have already attracted the community's attention. The government and society have also helped impoverished students by various means, which will definitely affect the mental health of impoverished students. What's more, $\mathrm{Qu}$ Xiaolin[13] deems that the lack of family education and their low comprehensive quality will lead to lower self-recognition, and she also points out three ways of cultivating self-confidence.

In response to self-confidence deficiency of impoverished college students, seven teachers who are engaged in the work of college counselors were interviewed. On this basis, an expert analysis group for the investigation of the reasons for the selfconfidence deficiency of impoverished college students was built. The expert group analyzed the reasons for the lack of self-confidence formed by the literature review and questionnaire survey, and adopted the Delphi method to reach a consensus. Therefore, in this paper, 14 factors for the lack of self-confidence of impoverished college students are picked out, as shown in Table I. Among them, the key issue of setting research is S0: the lack of self-confidence of impoverished college students. 
TABLE I. REASONS FOR THE LACK OF SELF-CONFIDENCE FOR IMPOVERISHED COLLEGE STUDENTS

\begin{tabular}{|c|c|c|c|}
\hline $\begin{array}{c}\text { Serial } \\
\text { numb } \\
\text { er }\end{array}$ & Cause factor & $\begin{array}{c}\text { Serial } \\
\text { numb } \\
\text { er }\end{array}$ & Cause factor \\
\hline$S_{1}$ & $\begin{array}{l}\text { Campus Environment } \\
\text { (The campus } \\
\text { environment in which } \\
\text { students live) }\end{array}$ & $S_{8}$ & $\begin{array}{l}\text { Not suitable for city } \\
\text { life } \\
\text { (Because most } \\
\text { impoverished students } \\
\text { come from rural areas) }\end{array}$ \\
\hline$S_{2}$ & $\begin{array}{l}\text { Family economy } \\
\text { (Household income) }\end{array}$ & $S_{9}$ & $\begin{array}{l}\text { External environment } \\
\text { (The environment } \\
\text { outside the school) }\end{array}$ \\
\hline$S_{3}$ & $\begin{array}{l}\text { Student character } \\
\text { (Lively or dull) }\end{array}$ & $S_{10}$ & $\begin{array}{l}\text { Self-factor } \\
\text { (Low self-recognition) }\end{array}$ \\
\hline$S_{4}$ & $\begin{array}{l}\text { Lack of school } \\
\text { education } \\
\text { (The school did not play } \\
\text { a guiding role) }\end{array}$ & $S_{11}$ & $\begin{array}{l}\text { Lack of previous } \\
\text { learning ability } \\
\text { (Often expressed as the } \\
\text { failure of the college } \\
\text { entrance examination) }\end{array}$ \\
\hline$S_{5}$ & $\begin{array}{l}\text { Psychological quality } \\
\text { (Become frustrated after } \\
\text { failure) }\end{array}$ & $S_{12}$ & $\begin{array}{l}\text { Family issues } \\
\text { (Divorce or quarrel) }\end{array}$ \\
\hline$S_{6}$ & $\begin{array}{l}\text { Social concept } \\
\text { (Attitude towards } \\
\text { society) }\end{array}$ & $S_{13}$ & $\begin{array}{l}\text { Society's attitude } \\
\text { towards impoverished } \\
\text { students } \\
\text { (Discrimination, etc.) }\end{array}$ \\
\hline$S_{7}$ & $\begin{array}{l}\text { The living environment } \\
\text { before the school } \\
\text { (Hardship, poverty, etc.) }\end{array}$ & $S_{14}$ & $\begin{array}{l}\text { Lack of } \\
\text { comprehensive quality } \\
\text { (Not good at } \\
\text { communication, etc.) }\end{array}$ \\
\hline
\end{tabular}

\section{Establish a Binary Relationship Set and Generate an} Adjacency Matrix

The binary relationship is based on the agreement of the research purpose, and the relationship between any two influencing factors $\left(S_{i}, S_{j}\right)$, recorded as $R_{i j}$ (abbreviated as $R$ ) needs to be discussed. All relationships can be broadly divided into two categories: $R$ and $\bar{R}$. To be specific, $R$ includes all reachable relationships, while $\bar{R}$ includes all unreachable relationships[14]. For any ordered pair $\left(S_{i}, S_{j}\right)$, if $S_{i}$ to $S_{j}$ is reachable, it belongs to $R$; otherwise it belongs to $\bar{R}$.

According to the analysis and investigation of experts, these 14 factors can build the following binary relationship sets:

$$
R=\left\{\begin{array}{lllll}
\left(S_{0}, S_{1}\right) & \left(S_{0}, S_{2}\right) & \left(S_{0}, S_{3}\right) & \left(S_{0}, S_{4}\right) & \left(S_{0}, S_{5}\right) \\
\left(S_{0}, S_{6}\right) & \left(S_{0}, S_{7}\right) & \left(S_{0}, S_{8}\right) & \left(S_{0}, S_{9}\right) & \left(S_{0}, S_{10}\right) \\
\left(S_{0}, S_{11}\right) & \left(S_{0}, S_{12}\right) & \left(S_{0}, S_{13}\right) & \left(S_{0}, S_{14}\right) & \left(S_{1}, S_{9}\right) \\
\left(S_{2}, S_{3}\right) & \left(S_{2}, S_{8}\right) & \left(S_{2}, S_{9}\right) & \left(S_{3}, S_{5}\right) & \left(S_{3}, S_{8}\right) \\
\left(S_{3}, S_{10}\right) & \left(S_{4}, S_{3}\right) & \left(S_{4}, S_{5}\right) & \left(S_{4}, S_{8}\right) & \left(S_{4}, S_{9}\right) \\
\left(S_{4}, S_{11}\right) & \left(S_{4}, S_{14}\right) & \left(S_{5}, S_{8}\right) & \left(S_{5}, S_{10}\right) & \left(S_{6}, S_{1}\right) \\
\left(S_{6}, S_{9}\right) & \left(S_{7}, S_{3}\right) & \left(S_{7}, S_{5}\right) & \left(S_{7}, S_{8}\right) & \left(S_{7}, S_{9}\right) \\
\left(S_{8}, S_{9}\right) & \left(S_{10}, S_{1}\right) & \left(S_{10}, S_{4}\right) & \left(S_{10}, S_{6}\right) & \left(S_{10}, S_{8}\right) \\
\left(S_{11}, S_{8}\right) & \left(S_{11}, S_{10}\right) & \left(S_{12}, S_{3}\right) & \left(S_{12}, S_{4}\right) & \left(S_{12}, S_{5}\right) \\
\left(S_{12}, S_{7}\right) & \left(S_{12}, S_{8}\right) & \left(S_{12}, S_{9}\right) & \left(S_{12}, S_{13}\right) & \left(S_{13}, S_{9}\right) \\
\left(S_{14}, S_{3}\right) & \left(S_{14}, S_{4}\right) & \left(S_{14}, S_{5}\right) & \left(S_{14}, S_{8}\right) & \left(S_{14}, S_{10}\right)
\end{array}\right\}
$$

Then, based on the relationship between the factors (support, inclusion, constraint, etc.), we establish an adjacency matrix $A$.

1) If there is an influence between $S_{i}$ and $S_{j}$, the value is 1 ; otherwise, it is 0 ;

2) If $S_{i}$ and $S_{j}$ have a great influence on each other, then both take 1. If the degree of mutual influence is strong, the big one takes 1 and the small takes 0 .

$$
\begin{aligned}
& S_{0}\left[\begin{array}{lllllllllllllll}
1 & 0 & 0 & 0 & 0 & 0 & 0 & 0 & 0 & 0 & 0 & 0 & 0 & 0 & 0
\end{array}\right]
\end{aligned}
$$

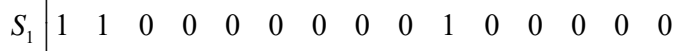

$$
\begin{aligned}
& \begin{array}{l|lllllllllllllll}
S_{2} & 1 & 0 & 1 & 1 & 0 & 0 & 0 & 1 & 1 & 1 & 0 & 0 & 0 & 0 & 0
\end{array}
\end{aligned}
$$

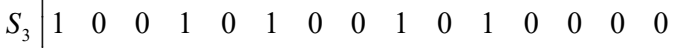

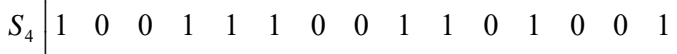

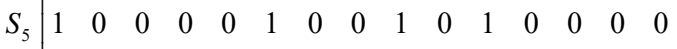

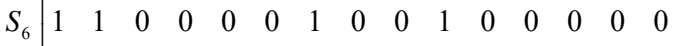

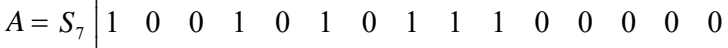

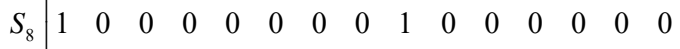

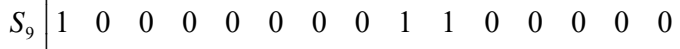

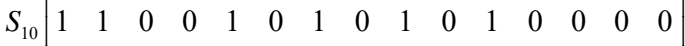

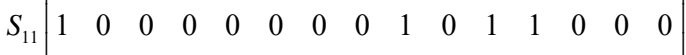

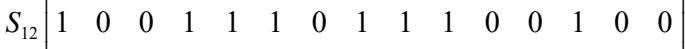

$$
\begin{aligned}
& \begin{array}{l}
S_{13} \\
S_{14}
\end{array}\left[\begin{array}{lllllllllllllll}
1 & 0 & 0 & 0 & 0 & 0 & 0 & 0 & 0 & 1 & 0 & 0 & 0 & 1 & 0 \\
1 & 0 & 0 & 1 & 1 & 1 & 0 & 0 & 1 & 0 & 1 & 0 & 0 & 0 & 1
\end{array}\right]
\end{aligned}
$$

\section{E. Division of Relationships Among Various Factors}

According to the calculation formula of the reachable matrix: $\quad M=(A+I)^{4}=(A+I)^{3} \neq(A+I)^{2} \quad, \quad$ we can get reachable matrix $M$, where $A$ is an adjacency matrix and $I$ is the identity matrix.

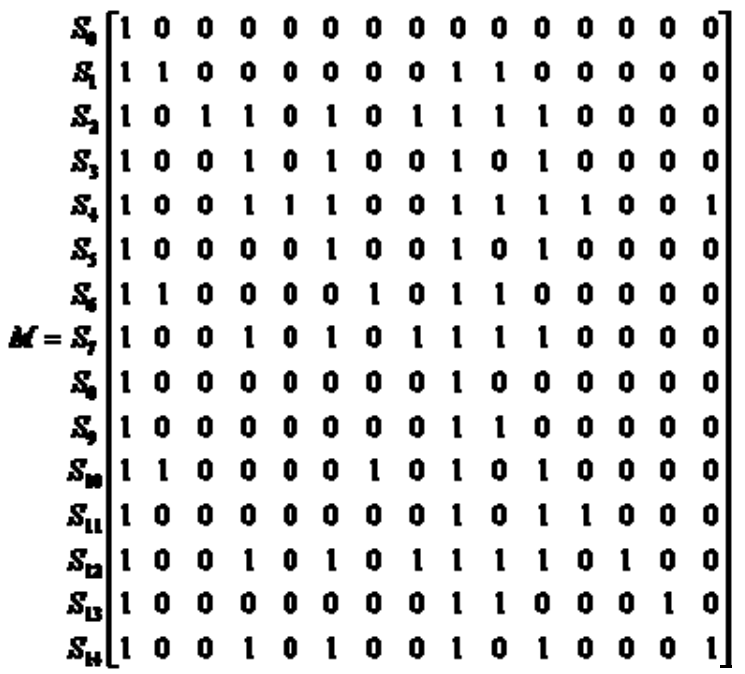

Inter-level division of the reachable matrix by the ISM method works on the matrix: First, calculate the reduced reachable matrix of reachable matrix $M$, when obtaining results that $M$ is the reduced reachable matrix, since there are no rows in $M$ that have the same elements as the columns. Second, change the diagonal element of $M$ to 0 to get matrix $M^{\prime}$. Find the elements corresponding to all rows in the $M^{\prime}$ matrix that are $0: S_{0}$. Then, $S_{0}$ constitutes a level 1 cause element set 
$\left(L_{1}=\left\{S_{0}\right\}\right)$; draw the rows and columns corresponding to $S_{0}$, and then find the elements corresponding to all rows in the matrix that are 0: $S_{8}$. Then, $S_{8}$ constitutes a second-level set of cause elements: $L_{2}=\left\{S_{8}\right\}$.

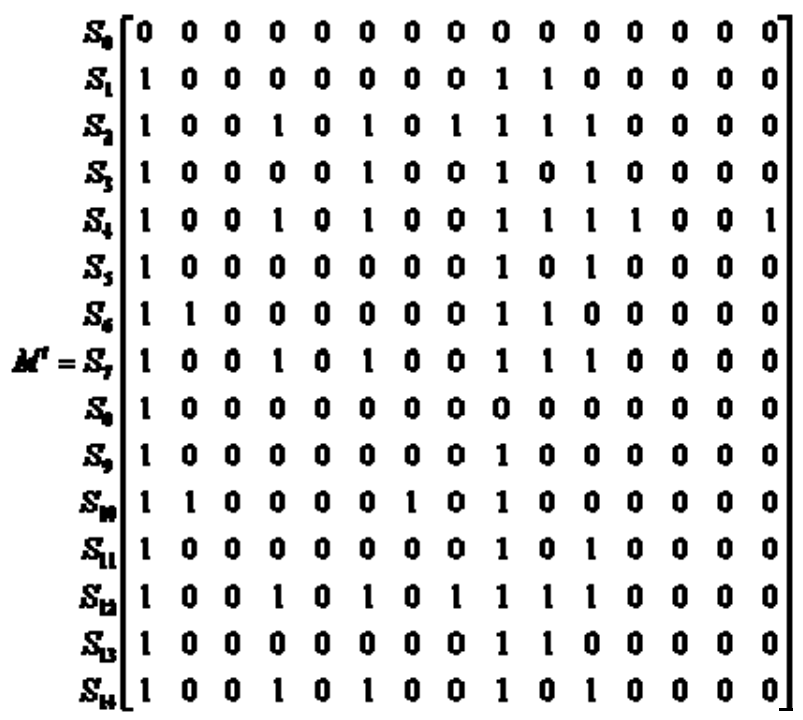

In the same way, the remaining elements can be layered, that is $L_{3}=\left\{S_{9}, S_{10}\right\}, \quad L_{4}=\left\{S_{1}, S_{5}, S_{6}, S_{11}, S_{13}\right\}, \quad L_{5}=\left\{S_{3}, S_{7}\right\}$, $L_{6}=\left\{S_{2}, S_{12}\right\}$.

\section{F. Interpretative Structural Model Construction}

According to the collection of causes and factors at all levels in Section D, an explanatory structural model for the lack of self-confidence in impoverished college students is established, as shown in Fig. 1.

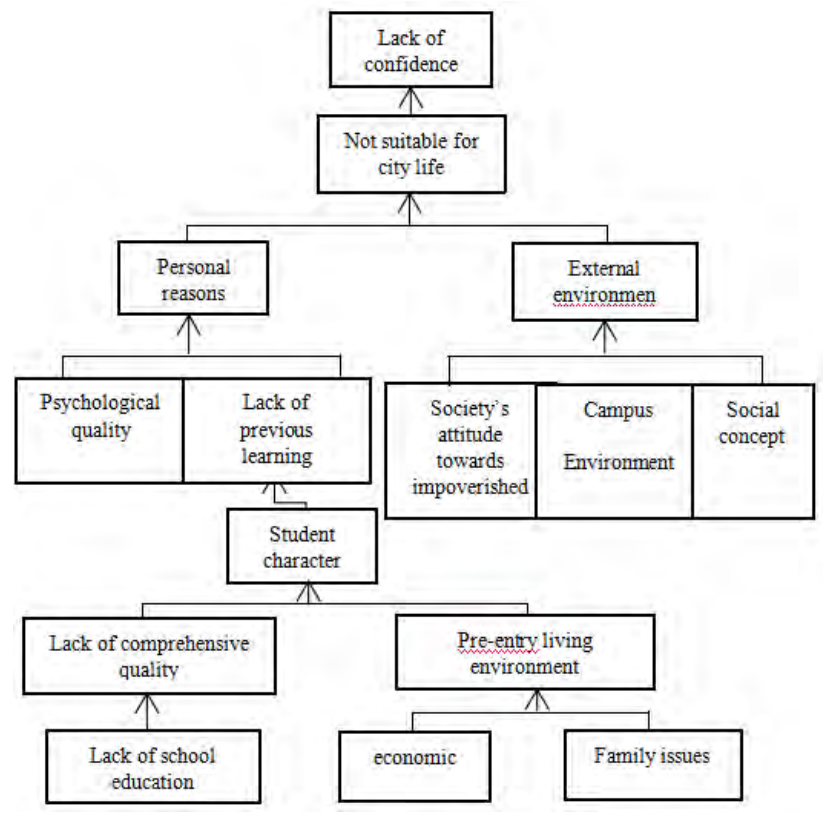

Fig. 1. The interpretative structural model concerning the reasons for the lack of self-confidence of impoverished college students

\section{THE ANALYSIS AND COUNTERMEASURES OF INTERPRETIVE STRUCTURAL MODELING}

According to the Interpretive Structural Modeling in Fig. 1, the reasons why impoverished college students lack selfconfidence comprise the multilevel structural modeling with 7 levels. Therefore, in this section, the reasons why most impoverished college students have no enough self-confidence will be analyzed.

By analyzing the whole modeling, it can be known that there are so many fundamental reasons that can make impoverished college students lose self-confidence. The reasons are impoverished college students' poor learning ability in the past, social attitudes towards impoverished college students, campus environment, the social concept, less confidence education in school, bad family economy and family problems. Among those reasons, society's attitude towards impoverished college students, campus environment, the social concept and family economy belong to the uncontrollable reasons, while impoverished college students' poor learning ability in the past, less confidence education in school and family problems are the controllable reasons. Those fundamental reasons why impoverished college students lack self-confidence are not affected by other reasons, and they are also the key reasons for the impoverished college students' lack of self-confidence. It is necessary to take some measures to solve this problem.

Through the hierarchical analysis on the relational structure of the modeling, it can be seen that the second factor is the surface reason which results in impoverished college students' lack of self-confidence. The second factor is that impoverished college students can't adapt to city life.

In reality, most impoverished college students come from remote villages. When they go into the city, for one thing, they find the great contrast between the simplicity of village life and the prosperity of city life; for another, they realize their economic conditions and comprehensive quality and abilities are different from those college students born in cities. Gradually, impoverished college students feel self-abased and lose self-confidence seriously. In addition, the external environment, such as the social attitude towards impoverished college students, also has a certain impact on the selfconfidence of impoverished college students. Although society's concern about impoverished college students has supported them to complete their study, it has a certain negative effect on impoverished college students when they are called "a special group". The college students identified as impoverished ones will believe that they are not as good as non-impoverished college students and even inferior to others in the university and social environment. As a result, impoverished college students can't adapt to city life. Thus, they will feel extremely self-abased. This proves that failing to integrate into city life is the most direct and fundamental reason why impoverished college students lack self-confidence.

The seventh level reasons (the lowest reasons) are the root reasons for impoverished college students' lack of selfconfidence. These primary reasons are bad family economy, family problems and less confidence education in school. About family economy, most impoverished college students 
are from rural areas where the consumption level is generally low and they have a narrow field of vision. After entering university, there are many students from big cities, and they are inevitably involved in some discussion and activities related to high consumption. Impoverished college students are reluctant to participate in or even deliberately avoid the discussion and activities, because of their families' financial difficulties. Invisibly, they develop a sense of inferiority. As they are introverted due to inferiority, they are unwilling to share their thoughts with classmates, which leads to a vicious circle. As time passes by, impoverished college students will have less self-confidence. As for family problems, some impoverished college students' family conditions are not good. Their parents divorced or often quarreled, and thus, their parents seldom communicate with them. In this case, impoverished college students received less care, and therefore, they couldn't shape cheerful characters. Finally, because of lacking self-confidence, it is difficult for the impoverished college students to communicate with and get along with others.

\section{COUNTERMEASURES AND SUGGESTIONS}

Combined with the above analysis and the root causes for the lack of self-confidence of impoverished college students, now, we propose some corresponding countermeasures.

(1) For family economy: In addition to financial aid such as student loans and grants, schools can also provide impoverished college students with jobs and practical positions, or encourage impoverished college students to work part-time without affecting their school work.

(2) For family issues: Schools should learn more about students' family situations in an indirect way and should also give more humanistic care to impoverished undergraduates who had an impoverished family environment. Student unions and organizations should play an important role and carry out psychological mutual assistance activities actively. Besides, we need truly give them the same kind of care and concern as their relatives. By organizing various group activities, impoverished students will actually feel the warmth of the school family, experience the sincere feelings among classmates, teachers and students, and cultivate their ability to communicate and get along with others, thereby helping them to eliminate the psychological barrier of inferiority.This requires a series of activities aimed at impoverished college students, when giving them opportunities to show themselves and cultivate the comprehensive quality and ability. In a word, the purpose is to improve their level of self-awareness and self-affirmation.

\section{REFERENCES}

[1] L.L. Wang, "Analysis of Psychological Problems of impoverished Students in Colleges and Universities and Adjustment Strategies," Science teaching, vol. 24, pp. 145-145, Dec. 2014.

[2] X.Y. Xu, R. Men, and Y. Zhang, "The Influence of the fees merged policy of Graduate Education Charges on Different Interest Groups and Its Countermeasures," Journal of Shenyang Institute of Technology, vol. 10(4), pp. 527-531, Oct. 2014.

[3] D.H. Cao and S.C. Huang, "Analysis and Countermeasure Research on the Lack of Self-confidence of Higher Vocational Students," Theoretical observation, vol. 7, pp. 159-160, June 2015.

[4] Y.H. Yang, "Cultivating Self-confidence: A New Base Point for Contemporary College Students' Self-education," Journal of Changjiang Normal University, vol. 28(8), pp. 127-129, Aug. 2012.

[5] J.N. Warfield, "Binary Matrices in System Modeling," IEEE Transactions on Systems Man \& Cybernetics, vol.5, pp. 441-449, 1973.

[6] S.J. Bai, System Engineering, Beijing, 2009, pp. 82-96.

[7] W.H. Jia, "Research on the Title of 'Psychological Poverty' of impoverished University Students," Heilongjiang Higher Education Research, vol. 02, pp. 115-117, Jan. 2011.

[8] Y.Q. Kong, "Impoverished Students in Colleges and Universities Should Grasp Three Degrees of Work," Jiangsu Higher Education, vol. 02, pp. 121-122, 1892.

[9] Z.H. Jiang, "The Performance of impoverished Students in Higher Vocational Colleges and Its Countermeasures," Educational exploration, vol. 08, pp. 144-145, 1963.

[10] J. Liu, "The Poverty Culture in University Campus - A Case Study of Y University impoverished Students," Modern university education, vol. 01, pp. 106-110, Jan. 2011.

[11] Z.Q. Pan, "Research on the Present Situation of impoverished Students' Self-Confidence in Private Universities," Culture and Education Research, vol. 06, pp. 215-217, May 2013.

[12] L. Zhu and M. Feng, "The influence of social support on mental health of impoverished college students," Journal of Longxi University, vol. 27(05), pp.42-44, Oct. 2011.

[13] X.L. Qu, L. Wang, and J. Wang, "Analysis of the Necessity and Approaches for Constructing impoverished Students' Positive Psychological Capital in Colleges and Universities," Journal of Heilongjiang Institute of Education, vol. 33(02), pp. 109-111, Feb. 2014.

[14] X.Y. Yang and J. Chen, "Interpretation Structure Model of Knowledge Flow Elements in Supply Chain Coordination," Soft Science, vol. 27(05), pp. 140-144, May 2013. 